\title{
Effects of calcium and magnesium on acute and chronic neurotoxicity caused by oxaliplatin: A meta-analysis
}

\author{
RUI AO ${ }^{1,2}$, YU-HUI WANG ${ }^{1}$, RUI-WEN LI $^{1}$ and ZHENG-RONG WANG ${ }^{1}$ \\ ${ }^{1}$ Key Laboratory of Chronobiology of Health Ministry, Basic and Forensic School, Sichuan University; \\ ${ }^{2}$ Department of Oncology, Sichuan Academy of Medical Sciences, Sichuan Provincial People's Hospital, \\ Chengdu, Sichuan 610041, P.R. China
}

Received May 21, 2012; Accepted August 14, 2012

DOI: $10.3892 / \mathrm{etm} .2012 .678$

\begin{abstract}
The primary toxicity of oxaliplatin is neurotoxicity. Calcium and magnesium $(\mathrm{Ca} / \mathrm{Mg})$ are reported to be beneficial in protecting against this adverse effect. However, the results obtained from clinical trials are not definitive. The aim of this study was to evaluate whether $\mathrm{Ca} / \mathrm{Mg}$ alleviates the neurotoxicity of oxaliplatin by performing a meta-analysis of the literature involving available randomized controlled trials. Systematic searches for trials were undertaken from the Cochrane Library, MEDLINE, CENTRAL, Embase, CBMdisc and CNKI databases without language limitations. The primary outcome was severe chronic neurotoxicity and the secondary outcome was acute neurotoxicity. Four randomized double-blind trials met the search criteria. The odds ratio (OR) comparing $\mathrm{Ca} / \mathrm{Mg}$ treatment with placebo was $0.44(0.23-0.85, \mathrm{P}=0.01)$ for severe chronic neurotoxicity of oxaliplatin (grade $\geq 2)$ and $0.41(0.11-$ $1.49, \mathrm{P}=0.18$ ) for acute neurotoxicity. In conclusion, $\mathrm{Ca} / \mathrm{Mg}$ treatment does not reduce the incidence of acute neurotoxicity of oxaliplatin, but does reduce the incidence of severe chronic neurotoxicity (grade $\geq 2$ ). No differences were observed in the outcomes of chemotherapy. Thus, $\mathrm{Ca} / \mathrm{Mg}$ treatment is recommended for use as an adjunct with oxaliplatin.
\end{abstract}

\section{Introduction}

Oxaliplatin is a third-generation platinum compound with structural differences from earlier platinates. It binds and cross-links with DNA, forming DNA adducts, thus inhibiting DNA replication and transcription. Chemotherapy regimens that include oxaliplatin are widely used in the treatment of colorectal cancer, having beneficial effects with response rates

Correspondence to: Professor Zheng-Rong Wang, Key Laboratory of Chronobiology of Health Ministry, Basic and Forensic School, Sichuan University, 12 Daxue Street, Chengdu, Shichuan 610041, P.R. China

E-mail: wangzhengrong555@sina.com

Key words: calcium and magnesium, neurotoxicity, oxaliplatin, chemotherapy as high as 53\% and a relatively low incidence of adverse effects, such as nausea, neutropenia, and vomiting $(1,2)$. However, neurotoxicity restricts its use and causes patient discomfort. The neurotoxicity observed with oxaliplatin can manifest as one of two distinct syndromes: a transient, acute syndrome that can appear during or shortly after infusion of oxaliplatin and a dose-limiting, cumulative sensory neuropathy.

The acute neuropathy occurs within minutes of infusion of oxaliplatin and is able to remain for 1-2 days. Frequently, this presents as paresthesia, tingling or an unusual sensation in the tongue, jaw spasms or limb stiffness, and may be triggered or aggravated by exposure to cold. The incidence of acute neuropathy ranges from 81.5 to $98 \%$ (3). The cumulative, chronic neurotoxicity presents as paresthesia and proprioceptive changes that do not resolve between cycles of chemotherapy, and occurs in approximately $15 \%$ of patients after cumulative oxaliplatin doses of $780-850 \mathrm{mg} / \mathrm{m}^{2}$, leading to functional impairment in approximately $10 \%$ of patients (2). The mechanism of oxaliplatin-induced neurotoxicity remains unclear.

One of the metabolites of oxaliplatin, oxalate, is a calcium chelator that is thought to have a deleterious effect on specific neuronal sodium channels, including voltage-gated and calcium-dependent channels (4-6). Certain agents are administered in an attempt to prevent neurotoxicity, such as glutathione, carbamazepine, gabapentin, amifostine, celecoxib, and a combination of calcium and magnesium $(\mathrm{Ca} / \mathrm{Mg}) . \mathrm{Ca} / \mathrm{Mg}$ is relatively widely used (7-11). $\mathrm{Ca} / \mathrm{Mg}$ is able to form a chelate with oxalate and reduce its effect on neuronal sodium channels. Intravenous calcium gluconate and magnesium sulfate are used at some institutions with the hopes of decreasing subsequent neuropathy (12-14). However, there has been some controversy about the effects of $\mathrm{Ca} / \mathrm{Mg}$ on the reduction of neurotoxicity and whether it decreases the antitumor activity of oxaliplatin $(15,16)$. The purpose of this study was to evaluate the effects of $\mathrm{Ca} / \mathrm{Mg}$ on the efficacy of oxaliplatin, using a meta-analysis of randomized trials, by assessing whether $\mathrm{Ca} / \mathrm{Mg}$ has the potential to reduce oxaliplatin-induced neurotoxicity.

\section{Materials and methods}

Selection criteria. Trials were eligible for inclusion based on the following criteria: i) patients received chemotherapy that included oxaliplatin; ii) trials were described as randomized 
Table I. Basic characteristics of trials included in this study.

\begin{tabular}{|c|c|c|c|c|c|c|c|c|}
\hline \multirow[b]{2}{*}{ Trial (Refs.) } & \multirow[b]{2}{*}{ Country } & \multirow[b]{2}{*}{ Site of tumor } & \multicolumn{2}{|c|}{ Enrolled patients } & \multirow{2}{*}{$\begin{array}{l}\text { Chemotherapy } \\
\text { regimen }\end{array}$} & \multicolumn{2}{|c|}{ Dose of $\mathrm{Ca} / \mathrm{Mg}$} & \multirow[b]{2}{*}{ Placebo } \\
\hline & & & $\mathrm{Ca} / \mathrm{Mg}$ & Control & & $\mathrm{Ca}$ & $\mathrm{Mg}$ & \\
\hline $\begin{array}{l}\text { Grothey et al } \\
2011 \text { (19) }\end{array}$ & USA & Colorectal & 50 & 52 & $\begin{array}{l}\text { FOLFOX-4, } \\
\text { FOLFOX-6 }\end{array}$ & $1 \mathrm{~g}$ & $1 \mathrm{~g}$ & $\begin{array}{c}\text { Identical } \\
\text { appearance }\end{array}$ \\
\hline $\begin{array}{l}\text { Dong et al } \\
2010(20)\end{array}$ & China & $\begin{array}{c}\text { Gastrointestinal } \\
\text { tract }\end{array}$ & 29 & 31 & FOLFOX-4 & $1 \mathrm{~g}$ & $1 \mathrm{~g}$ & Normal saline \\
\hline $\begin{array}{l}\text { Ishibashi et al } \\
2010(21)\end{array}$ & Japan & Colorectal & 17 & 16 & mFOLFOX-6 & $0.85 \mathrm{~g}$ & $0.72 \mathrm{~g}$ & $5 \%$ glucose \\
\hline $\begin{array}{l}\text { Chay et al } \\
2010(22)\end{array}$ & Singapore & Colorectal & 13 & 14 & $\begin{array}{l}\text { XELOX, } \\
\text { FOLFOX-4 }\end{array}$ & $1 \mathrm{~g}$ & $1 \mathrm{~g}$ & Normal saline \\
\hline
\end{tabular}

FOLFOX-4, 2-h infusion of leucovorin $\left(200 \mathrm{mg} / \mathrm{m}^{2} / \mathrm{d}\right)$ followed by a fluorouracil bolus $\left(400 \mathrm{mg} / \mathrm{m}^{2} / \mathrm{d}\right)$ and $22-\mathrm{h}$ infusion $\left(600 \mathrm{mg} / \mathrm{m}^{2} / \mathrm{d}\right) \mathrm{for}$ two consecutive days every 2 weeks, together with oxaliplatin $85 \mathrm{mg} / \mathrm{m}^{2}$ as a 2-h infusion on day 1; mFOLFOX-6: 2-h infusion of leucovorin $\left(400 \mathrm{mg} / \mathrm{m}^{2}\right)$ followed by a fluorouracil bolus $\left(400 \mathrm{mg} / \mathrm{m}^{2}\right)$ and $46-\mathrm{h}$ infusion $\left(2,400 \mathrm{mg} / \mathrm{m}^{2}\right)$ every 2 weeks, together with oxaliplatin $85 \mathrm{mg} /$ $\mathrm{m}^{2}$ as a 2-h infusion on day 1; XELOX, oral capecitabine $1000 \mathrm{mg} / \mathrm{m}^{2}$ twice a day for Days $1-14$ and oxaliplatin $130 \mathrm{mg} / \mathrm{m}^{2} \mathrm{on} \mathrm{Day} 1 \mathrm{every} 21$ days; $\mathrm{Ca} / \mathrm{Mg}$, calcium gluconate and magnesium sulfate, which were used on the first day of chemotherapy.

clinical trials; iii) published trials included a treatment group receiving $\mathrm{Ca} / \mathrm{Mg}$ during chemotherapy and a control group that did not receive $\mathrm{Ca} / \mathrm{Mg}$; and iv) the evaluation criteria of chronic neurotoxicity of oxaliplatin in the published trials adopted the neurotoxicity grade of the National Cancer Institute's Common Toxicity Criteria (NCI-CTC) version 3.0, or included the acute neuropathy of oxaliplatin (Sanofi-Aventis: Eloxatin: Assessing neuropathy. Available at http://www.eloxatin.com/. Accessed February 11, 2010). Trials were excluded if they did not meet the criteria above and included the following: i) they involved animal or in vitro studies; ii) they did not represent primary research (e.g., review articles, letters to the editor); or iii) they represented duplicate publications of other studies previously identified in our systematic evaluation.

Search strategy. Retrieval of trials was performed through searches of MEDLINE (January 1966 to October 2011), Embase (January 1966 to October 2011), CBMdisk (Chinese Biomedical Database; January 1978 to October 2011), CNKI (Chinese National Knowledge Infrastructure; January 1979 to October 2011), and CENTRAL (the Cochrane Central Register of Controlled Trials; January 1966 to October 2011). The databases were searched without language limitations. The search was designed to initially find all trials involving the following terms: oxaliplatin or FOLFOX or FOLFOX4 or FOLFOX6 or XELOX and calcium or magnesium or Calcium gluconate or $\mathrm{Ca} / \mathrm{Mg}$. A manual search for general reviews on neurotoxicity of oxaliplatin and references from published clinical trials was conducted. The search results were downloaded to reference databases and screened further.

Outcome measurements. Outcome measurements of these trials included the following: i) the main endpoint was the proportion of severe, chronic neurotoxicity (grade $\geq 2$ ); ii) the second endpoint was the extent of acute neuropathy; and iii) the third endpoint was the effects of chemotherapy.
Table II. National Cancer Institute common toxicity criteria (NCI-CTC).

\begin{tabular}{|c|c|}
\hline Scale & NCI-CTC grading for neuropathy \\
\hline Grade 1 & $\begin{array}{l}\text { Asymptomatic, loss of deep tendon, } \\
\text { reflexes, or paresthesia (including } \\
\text { tingling), but not interfering } \\
\text { with function }\end{array}$ \\
\hline Grade 2 & $\begin{array}{l}\text { Sensory alteration or paresthesia } \\
\text { (including tingling) interfering with } \\
\text { function, but not ADL }\end{array}$ \\
\hline Grade 3 & $\begin{array}{l}\text { Sensory alteration or paresthesia } \\
\text { interfering with ADL }\end{array}$ \\
\hline Grade 4 & Disabling \\
\hline
\end{tabular}

NCI-CTC, National Cancer Institute's Common Toxicity Criteria. ADL, activities of daily living.

These data were extracted from actual numbers reported in the trials.

\section{Review methods}

Data checking. Methodological quality of trials was evaluated according to the Jadad quality scores (17), which include secure method of randomization, allocation concealment, patient and observer blinding, and withdrawal. Based on these criteria, the studies were divided into a high-quality group (score $\geq 4$ ) and a low-quality group (score $<4$ ). Two reviewers independently assessed the eligibility of each trial.

Data extraction. Each study included in the meta-analysis was read and the data were extracted and cross-checked independently by two reviewers, and discrepancies were resolved by discussion. The following information was 
Table III. Quality assessment of trials included in this study.

\begin{tabular}{|c|c|c|c|c|c|}
\hline Trial (Refs.) & Randomization & Allocation concealment & Blind & Withdrawal and dropout & Jadad score \\
\hline $\begin{array}{l}\text { Grothey et al } \\
2011 \text { (19) }\end{array}$ & Without details & Without details & Double-blind & Well reported & 6 \\
\hline $\begin{array}{l}\text { Dong et al } \\
2010(20)\end{array}$ & Without details & Without details & Double-blind & Without details & 4 \\
\hline $\begin{array}{l}\text { Ishibashi et al } \\
2010(21)\end{array}$ & Well reported & Appropriate & Double-blind & Well reported & 7 \\
\hline $\begin{array}{l}\text { Chay et al } \\
2010(22)\end{array}$ & Without details & Without details & Without details & Well reported & 4 \\
\hline
\end{tabular}

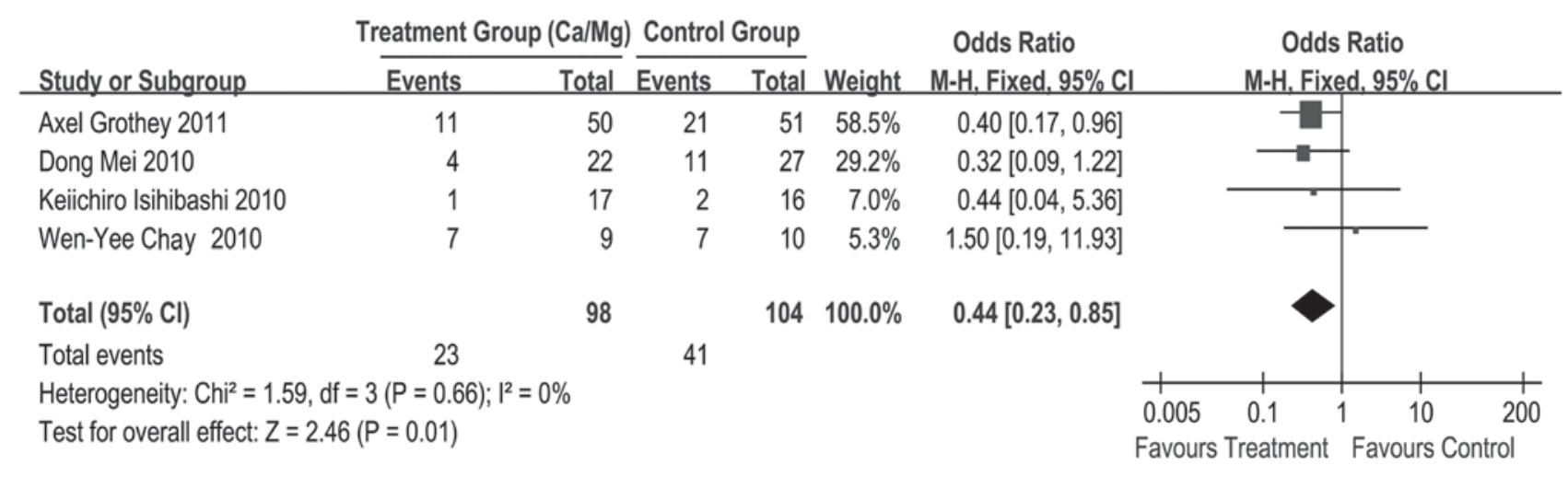

Figure 1. Meta-analysis of chronic neurotoxicity of oxaliplatin. Chemotherapy with calcium/magnesium $(\mathrm{Ca} / \mathrm{Mg})$ versus chemotherapy with placebo.

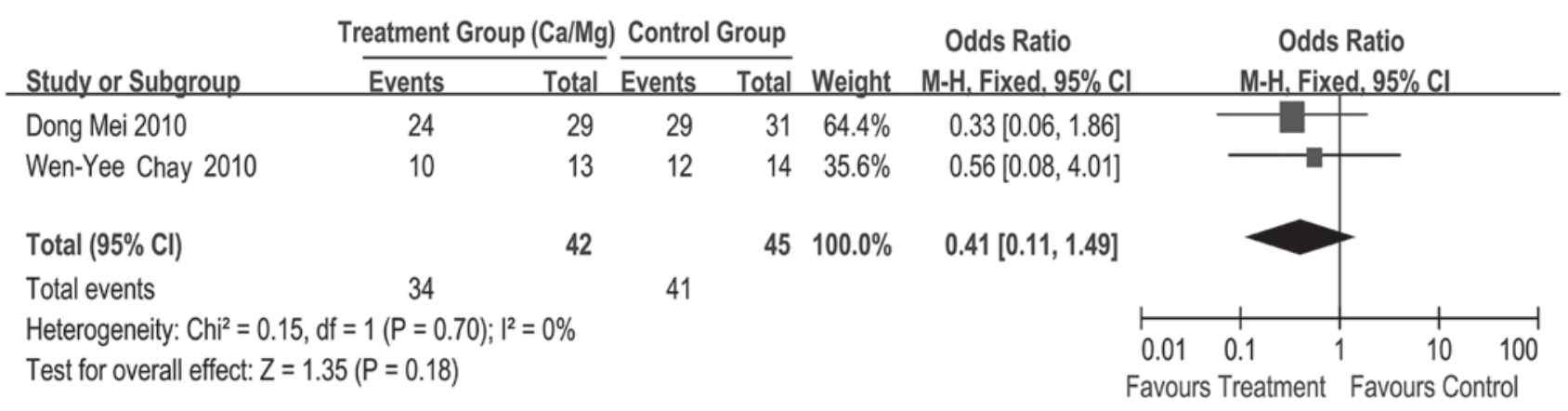

Figure 2. Meta-analysis of acute neurotoxicity of oxaliplatin. Chemotherapy with calcium/magnesium $(\mathrm{Ca} / \mathrm{Mg})$ versus chemotherapy with placebo.

extracted from each included trial: i) characteristics of the methods used (randomization procedure, allocation concealment, blinding procedure, withdrawal and reasons); ii) the number of patients allocated and patient characteristics; iii) the regimen of chemotherapy and the number of cycles patients received; and iv) the extent of acute and chronic neurotoxicity.

Statistical analysis. Patients were pooled for the meta-analysis by a biostatistician. Analysis was performed using RevMan 5.0. If $\mathrm{P}>0.10$ or $\mathrm{I}^{2} \leq 50 \%$, heterogeneity of the trial was considered acceptable and differences between the OR and 95\% CI were computed by the fixed-effects model. If $\mathrm{P} \leq 0.10$ or $\mathrm{I}^{2}>50 \%$, differences between the OR and $95 \%$ CI were computed by the random-effects model.

\section{Results}

Description of trials. A total of 135 studies were retrieved. Only five studies were eligible for our meta-analysis. One trial was excluded due to insufficient data, as only grade 3 chronic neurotoxicity was evaluated. The remaining four trials were described as randomized, doubled-blind studies. Two of the four trials evaluated the incidence of acute neurotoxicity caused by oxaliplatin, and chronic neurotoxicity was evaluated in all four trails according to the NCI-CTC criteria. Chronic neurotoxicity of grade $\geq 2$ was considered as severe neurotoxicity. A total of 202 patients completed the evaluation for chronic neurotoxicity. Two of the four trials evaluated chronic neurotoxicity at the end of the sixth cycle of chemotherapy, and 
all patients were required to have completed at least two cycles of chemotherapy and were expected to complete 12 cycles or six months of chemotherapy. For chemotherapy outcome, one trial compared the treatment outcome between the two groups according to the response evaluation criteria in solid tumors (RECIST) (18), and one trial compared the risk of recurrence between the two groups whose patients underwent tumor resection. Characteristics of the included trials are listed in Table I. NCI-CTC criteria are listed in Table II.

Meta-analysis outcomes. The four trials included in this study evaluated chronic neurotoxicity of oxaliplatin by NCI-CTC 3.0. The pooled analysis showed that compared with placebo, $\mathrm{Ca} / \mathrm{Mg}$ significantly reduced the number of patients with a neurotoxicity grade of $\geq 2$, with an OR of 0.44 (95\% CI, $0.23-0.85)$. The fixed-effects model was used because heterogeneity of the results was acceptable $\left(\mathrm{P}=0.66, \mathrm{I}^{2}=0\right)$ (Fig. 1).

We identified two trials containing evaluation of acute neurotoxicity of oxaliplatin. The fixed-effects model was used $\left(\mathrm{P}=0.70, \mathrm{I}^{2}, 0\right)$. Analysis showed that $\mathrm{Ca} / \mathrm{Mg}$ had no effect on the acute neurotoxicity of oxaliplatin, with an OR of 0.41 (95\% CI, 0.11-1.49) (Fig. 2).

Treatment outcomes of chemotherapy. The effects of chemotherapy on unresectable tumors in both the placebo and $\mathrm{Ca}$ / $\mathrm{Mg}$ groups were compared in one trial. No significant differences were observed in the response rates, disease control rates, or survival times between the two groups. The effects of adjuvant chemotherapy were observed in another trial (22), the results of which showed that the use of $\mathrm{Ca} / \mathrm{Mg}$ did not seem to increase the recurrence of tumors.

\section{Discussion}

The meta-analysis, which was based on data provided by four randomized trials, compared the administration of $\mathrm{Ca} /$ $\mathrm{Mg}$ with placebo regarding protection from the neurotoxicity of oxaliplatin. $\mathrm{Ca} / \mathrm{Mg}$ did not show any marked benefit against acute neurotoxicity, although a significant effect on the reduction of severe chronic neurotoxicity caused by oxaliplatin was evident. Chemotherapy regimens including oxaliplatin are currently considered to be a standard of care in the management of adjuvant and metastatic colorectal cancers $(1,23,24)$. However, the neurotoxicity that often occurs alters patient quality of life and may lead to postponement or even interruption of oxaliplatin therapy.

In 2004, Gamelin et al published a clinical trial concluding that calcium and magnesium infusion significantly reduced the incidence and severity of peripheral neuropathy secondary to oxaliplatin (13). Those authors administered $1 \mathrm{~g}$ of calcium gluconate and $1 \mathrm{~g}$ of magnesium sulfate as an infusion 1 or $2 \mathrm{~h}$ prior to oxaliplatin infusion and after the oxaliplatin infusion finished. In their retrospective cohort of 161 patients treated with oxaliplatin plus 5-fluorouracil/leucovorin for advanced colorectal cancer, the percentage of patients with grade 3 distal paresthesia was significantly lower in the $\mathrm{Ca} / \mathrm{Mg}$ group (7 vs. $26 \%, P=0.001)(13)$.

In a retrospective study by Knijn et al (25), 755 previously untreated, advanced colorectal cancer patients were enrolled; the $\mathrm{Ca} / \mathrm{Mg}^{+}$group comprised 551 patients and the
$\mathrm{Ca} / \mathrm{Mg}^{-}$group comprised 181 patients. Incidence of all grades of neurotoxicity in the $\mathrm{Ca} / \mathrm{Mg}^{+}$and $\mathrm{Ca} / \mathrm{Mg}^{-}$groups was 85 and $92 \%$, respectively $(\mathrm{P}=0.02)$, and the incidence of neurotoxicity of grade $\geq 2$ was 40 and $45 \%$, respectively ( $\mathrm{P}=0.22$ ). The median progression-free survival (PFS) in the $\mathrm{Ca} / \mathrm{Mg}^{+}$ versus $\mathrm{Ca} / \mathrm{Mg}^{-}$group was 10.1 versus 10.7 months $(\mathrm{P}=0.92)$, the median OS was 19.8 versus 20.7 months $(\mathrm{P}=0.10)$, and the response rate was 43.1 versus $50 \%(\mathrm{P}=0.11)$. The results also demonstrate that $\mathrm{Ca} / \mathrm{Mg}$ infusions significantly reduce the likelihood of all grades of neurotoxicity, but had no significant effect on the efficacy of treatment (25).

In contrast to the present results, the CONCEPT (Combined Oxalipatin Neurotoxicity Prevention Trial) study, a clinical trial of patients who were administered $\mathrm{Ca} / \mathrm{Mg}$ infusions to reduce the neurotoxicity resulting from oxaliplatin treatment, was prematurely terminated in 2007 after it had been ongoing for 2 years. The independent data monitoring committee found that the $\mathrm{Ca} / \mathrm{Mg}$ infusion reduced the efficacy of the chemotherapy regimen (14). Subsequently, Gamelin stated that $\mathrm{Ca} / \mathrm{Mg}$ infusion has no impact on oxaliplatin efficacy (26). Thus, controversy exists regarding the value of $\mathrm{Ca} / \mathrm{Mg}$, focusing on whether $\mathrm{Ca} / \mathrm{Mg}$ reduces the incidence of neurotoxicity or affects the treatment outcomes of oxaliplatin, and the concern that some of the prospective, randomized doubleblinded trials did not show convincing evidence supporting the use of $\mathrm{Ca} / \mathrm{Mg}$.

On the basis of our meta-analysis of high-quality prospective trails, we suggest that $\mathrm{Ca} / \mathrm{Mg}$ is able to reduce the incidence of severe chronic neurotoxicity of oxaliplatin without any evidence that it has an impact on efficacy. Accordingly, we suggest $\mathrm{Ca} / \mathrm{Mg}$ infusions be continued in order to reduce oxaliplatin neurotoxicity.

\section{References}

1. de Gramont A, Figer A, Seymour M, et al: Leucovorin and fluorouracil with or without oxaliplatin as first-line treatment in advanced colorectal cancer. J Clin Oncol 18: 2938-2947, 2000.

2. Giacchetti S, Perpoint B, Zidani R, et al: Phase III multicenter randomized trial of oxaliplatin added to chronomodulated fluorouracil-leucovorin as first-line treatment of metastatic colorectal cancer. J Clin Oncol 18: 136-147, 2000.

3. Cersosimo RJ: Oxaliplatin-associated neuropathy: a review. Ann Pharmacother 39: 128-135, 2005.

4. Adelsberger H, Quasthoff S, Grosskreutz J, Lepier A, Eckel F and Lers C: The chemotherapeutic oxaliplatin alters voltage-gated $\mathrm{Na}(+)$ channel kinetics on rat sensory neurons. Eur J Pharmacol 406: 25-32, 2000.

5. Gauchan P, Andoh T, Ikeda K, et al: Mechanical allodynia induced by paclitaxel, oxaliplatin and vincristine: different effectiveness of gabapentin and different expression of voltagedependent calcium channel alpha(2)delta-1 subunit. Biol Pharm Bull 32: 732-734, 2009.

6. Grolleau F, Gamelin L, Boisdron-Celle M, Lapied B, Pelhate M and Gamelin E: A possible explanation for a neurotoxic effect of the anticancer agent oxaliplatin on neuronal voltage-gated sodium channels. J Neurophysiol 85: 2293-2297, 2001.

7. Cascinu S, Catalano V, Cordella L, et al: Neuroprotective effect of reduced glutathione on oxaliplatin-based chemotherapy in advanced colorectal cancer: a randomized, double-blind, placebo controlled trial. J Clin Oncol 16: 3478-3483, 2002.

8. Eckel F, Schmelz R, Adelsberger H, Erdmann J, Quasthoff S and Lersch C: Prevention of oxaliplatin neuropathy by carbamazepine. A pilot study. Dtsch Med Wochenschr 127: 78-82, 2003.

9. Mariani G, Garrone O, Granetto C, Numico G, LaCiura P and Grecchi G: Oxaliplatin induced neuropathy: could gabapentin be the answer? Proc Am Soc Clin Oncol 19: abs. 2397, 2000. 
10. Penz M, Kornek GV, Raderer M, Ulrich-Pur H, Fiebiger W and Scheithauer W: Subcutaneous administration of amifostine: a promising therapeutic option in patients with oxaliplatin-related peripheral sensitive neuropathy. Ann Oncol 12: 421-422, 2001.

11. Agafitei RD, Schneider S, Iqbal S, Yang D, Groshen S and Lenz HJ: Effect of celecoxib on neurotoxicity in patients with metastatic colorectal cancer treated with 5-FU/oxaliplatin (CIFOX). J Clin Oncol 22: 3600, 2004.

12. Muto O, Ando H, Ono T, et al: Reduction of oxaliplatin-related neurotoxicity by calcium and magnesium infusions. Gan To Kagaku Ryoho 34: 579-581, 2007.

13. Gamelin L, Boisdron-Celle M, Delva R, et al: Prevention of oxaliplatin-related neurotoxicity by calcium and magnesium infusions: a retrospective study of 161 patients receiving oxaliplatin combined with 5-fluorouracil and leucovorin for advanced colorectal cancer. Clin Cancer Res 10: 4055-4061, 2004.

14. Hochster HS, Grothey A and Childs BH: Use of calcium and magnesium salts to reduce oxaliplatin-related neurotoxicity. J Clin Oncol 25: 4028-4029, 2007.

15. Kurniali PC, Luo LG and Weitberg AB: Role of calcium/ magnesium infusion in oxaliplatin-based chemotherapy for colorectal cancer patients. Oncology 24: 289-292, 2010.

16. Khattak MA: Calcium and magnesium prophylaxis for oxaliplatin-related neurotoxicity: is it a tradeoff between drug efficacy and toxicity? Oncologist 16: 1780-1783, 2011.

17. Jadad AR, Moore RA, Carroll D, et al: Assessing the quality of reports of randomized clinical trials: is blinding necessary? Control Clin Trials 17: 1-12, 1996.

18. Therasse P, Arbuck SG, Eisenhauer EA, et al: New guidelines to evaluate the response to treatment in solid tumors. J Natl Cancer Inst 92: 205-216, 2000.
19. Grothey A, Nikcevich DA, Sloan JA, et al: Intravenous calcium and magnesium for oxaliplatin-induced sensory neurotoxicity in adjuvant colon cancer: NCCTG N04C7. J Clin Oncol 29: 421-427, 2011.

20. Dong M, Xing PY, Liu P, Feng FY and Shi YK: Assessment of the protective effect of calcium-magnesium infusion and glutathione on oxaliplatin-induced neurotoxicity. Zhonghua Zhong Liu Za Zhi 32: 208-211, 2010.

21. Ishibashi K, Okada N, Miyazaki T, Sano M and Ishida H: Effect of calcium and magnesium on neurotoxicity and blood platinum concentrations in patients receiving mFOLFOX6 therapy: a prospective randomized study. Int J Clin Oncol 15: 82-87, 2010.

22. Chay WY and Tan SH: Use of calcium and magnesium infusions in prevention of oxaliplatin induced sensory neuropathy. AsiaPacific J Clin Oncol 6: 270-277, 2010.

23. Meyerhardt JA and Mayer RJ: Systemic therapy for colorectal cancer. N Engl J Med 352: 476-487, 2005.

24. Andre T, Boni C, Mounedji-Boudiaf L, et al: Oxalipatin, fluorouracil, and leucovorin as adjuvant treatment for color cancer. $\mathrm{N}$ Engl J Med 350: 2343-2351, 2004.

25. Knijn N, Tol J, Koopman M, et al: The effect of prophylactic calcium and magnesium infusions on the incidence of neurotoxicity and clinical outcome of oxaliplatin-based systemic treatment in advanced colorectal cancer patients. Eur J Cancer 47: 369-374, 2011.

26. Gamelin L: Oxaliplatin-related neurotoxicity: interest of calcium-magnesium infusion and no impact on its efficacy. J Clin Oncol 26: 1189-1190, 2008 